\title{
RELICT OLIVINES IN MICROMETEORITES: PRECURSORS AND INTERACTIONS IN THE EARTH'S
} ATMOSPHERE

\author{
N. G. Rudraswami ${ }^{1}$, M. Shyam Prasad ${ }^{1}$, S. Dey ${ }^{1,2}$, D. Fernandes ${ }^{1}$, J. M. C. Plane $^{3}$, W. Feng ${ }^{3}$, S. Taylor ${ }^{4}$, and \\ J. D. CARRILlo-SÁNCHEZ ${ }^{3}$ \\ ${ }^{1}$ National Institute of Oceanography (Council of Scientific and Industrial Research), Dona Paula, Goa 403004, India; rudra@nio.org \\ 2 Indian Institute of Technology, Roorkee, Uttarakhand 247667, India \\ ${ }^{3}$ School of Chemistry, University of Leeds, Leeds LS2 9JT, UK \\ ${ }^{4}$ Cold Regions Research and Engineering Laboratory, 72 Lyme Road, Hanover, New Hampshire 03755-1290, USA \\ Received 2016 June 9; revised 2016 September 3; accepted 2016 September 6; published 2016 November 9
}

\begin{abstract}
Antarctica micrometeorites $(\sim 1200)$ and cosmic spherules ( 5000) from deep sea sediments are studied using electron microscopy to identify Mg-rich olivine grains in order to determine the nature of the particle precursors. Mg-rich olivine ( $\mathrm{FeO}<5 \mathrm{wt} \%)$ in micrometeorites suffers insignificant chemical modification during its history and is a well-preserved phase. We examine 420 forsterite grains enclosed in 162 micrometeorites of different types —unmelted, scoriaceous, and porphyritic - in this study. Forsterites in micrometeorites of different types are crystallized during their formation in solar nebula; their closest analogues are chondrule components of CV-type chondrites or volatile rich $\mathrm{CM}$ chondrites. The forsteritic olivines are suggested to have originated from a cluster of closely related carbonaceous asteroids that have $\mathrm{Mg}$-rich olivines in the narrow range of $\mathrm{CaO}(0.1-0.3 \mathrm{wt} \%), \mathrm{Al}_{2} \mathrm{O}_{3}$ $(0.0-0.3 \mathrm{wt} \%), \mathrm{MnO}(0.0-0.3 \mathrm{wt} \%)$, and $\mathrm{Cr}_{2} \mathrm{O}_{3}(0.1-0.7 \mathrm{wt} \%)$. Numerical simulations carried out with the Chemical Ablation Model (CABMOD) enable us to define the physical conditions of atmospheric entry that preserve the original compositions of the Mg-rich olivines in these particles. The chemical compositions of relict olivines affirm the role of heating at peak temperatures and the cooling rates of the micrometeorites. This modeling approach provides a foundation for understanding the ablation of the particles and the circumstances in which the relict grains tend to survive.
\end{abstract}

Key words: atmospheric effects - Earth - interplanetary medium - minor planets, asteroids: general - Sun: general

Supporting material: machine-readable table

\section{INTRODUCTION}

Extraterrestrial dust particles in sizes ranging from tens of micrometeres to a few millimeters originate from two likely sources: (a) the asteroid belt where the dust is generated from collisions between large bodies; and (b) cometary bodies releasing dust due to solar heating during their perihelional passage (Brownlee 2001). The understanding of the specific types of source that contribute to the dust is still evolving. There is general disagreement among researchers whether a large component comes from the asteroid belt or from cometary bodies (Brownlee 2001; Kortenkamp et al. 2001; Nesvorný et al. 2010, 2011). However, the Zodiacal Cloud (Nesvorný et al. 2010, 2011) considers the Jupiter Family of Comets to be the main contributor, with minor contributions from the asteroid belt and the Halley-type comets. The larger orbital eccentricities do not allow cometary particles to get confined to the Earth's resonance orbit (Dermott et al. 1994; Reach et al. 1997; Brownlee 2001). Cometary dust has much higher entry velocity than asteroidal dust and in the process loses the gravitational focusing required to be captured by the Earth (Flynn 1989). In addition, the cometary particles that got trapped in the Earth's resonance orbit will have high entry velocities and undergo large-scale ablation during atmospheric entry, thereby losing their properties and identity (Flynn 1989a, 1989b; Brownlee 2001; Kortenkamp et al. 2001). On the other hand, the gravitational focusing is more in asteroidal dust and these particles enter the Earth's resonance orbit at much lower velocities (Flynn 1989a, 1989b). Moreover, the collision between asteroids generates a large amount of dust that swarms into the resonance orbit of the
Earth. It is estimated that of the $\sim 30,000$ tons/annum of meteoroids that enter the Earth's atmosphere (Love \& Brownlee 1993; Peucker-Ehrenbrink \& Ravizza 2000; Plane 2012), only $\sim 3000$ tons/annum reaches the surface, of which a large percentage of the particles undergo heating and are chemically altered losing their distinctive properties, which otherwise could have led to an understanding of the precursors (Taylor et al. 1998, 2007). The new estimates of the micrometeorites' accretion rate $\sim 16000$ tons/annum was suggested based on micrometeorites collected from Antarctica and noble gas measurements done on residue (Yada et al. 2004). The model for the zodiacal cloud also corroborates the above new estimates (Nesvorný et al. 2011).

Much information on micrometeorites can be acquired from relict grains preserved in the particles that have escaped significant atmospheric heating. The relict grains, especially those composed of $\mathrm{Mg}$-rich olivine with $\mathrm{FeO}$ content of $<5 \mathrm{wt} \%$, are markedly different from other grains in the same micrometeorite. Mg-rich olivines are dominant in large numbers of micrometeorites. Investigating the nature of relict grains is therefore useful for identifying the range of chondrites that contributes to the flux of micrometeorites (Steele et al. 1985a, 1985b; Steele 1992). The survival of the relict grains also constrains the temperature the particle may have experienced during atmospheric entry. $\mathrm{Mg}$-rich relict grains are commonly found in chondrules and fragments embedded in the matrix of carbonaceous chondrites, but rarely in ordinary chondrites. Identification of relict olivine is therefore an important link to a particle's thermal history during atmospheric entry, as well as the precursor meteoroid. We therefore 
Table 1

Chemical Composition (wt\%) of Relict Olivine Grains in Antarctica Micrometeorites and Deep Sea Cosmic Spherules

\begin{tabular}{lcccc}
\hline \hline ID & $\begin{array}{c}\mathrm{Na}_{2} \mathrm{O} \\
(\%)\end{array}$ & $\begin{array}{c}\mathrm{MgO} \\
(\%)\end{array}$ & $\begin{array}{c}\mathrm{Al}_{2} \mathrm{O}_{3} \\
(\%)\end{array}$ & $\begin{array}{c}\mathrm{SiO}_{2} \\
(\%)\end{array}$ \\
\hline P59 & 0.01 & 55.22 & 0.18 & 42.56 \\
P59 & 0.00 & 52.11 & 0.17 & 42.85 \\
P65 & 0.01 & 53.44 & 0.14 & 42.10 \\
P71 & 0.00 & 51.04 & 0.02 & 42.30 \\
P88 & 0.01 & 53.82 & 0.01 & 42.95 \\
\hline
\end{tabular}

Note. The full version contains chemical compositions of relict olivine grains for both the Antarctica micrometeorites and Deep sea cosmic spherules.

(This table is available in its entirety in machine-readable form.)

confine our discussion to the understanding of precursors and atmospheric entry parameters that facilitate survival of the grains. The composition of minor elements present in the relict mineral helps narrow down the precursor with greater precision than the bulk chemical composition (Steele et al. 1985a, 1985b; 1992), particularly because Mg-rich olivine can be compared with Mg-rich olivine in chondritic components. In contrast, the bulk chemical composition of a particle may alter depending on the heating experienced during atmospheric entry, and is typically close to CI composition (Kurat et al. 1994; Brownlee et al. 1997; Taylor et al. 2000; Rudraswami et al. 2012, 2014). Earlier studies were limited by statistics due to the small number of relict grains analyzed (Steele et al. 1985a, 1985b; 1992). The present comprehensive study with a larger number of samples allows us to make a stronger case for understanding the nature of the precursor.

The forsteritic olivine of micrometeorites collected from Antarctica and deep sea sediments has been studied previously to discern the nature of the precursor and its behavior during atmospheric entry (Taylor et al. 1998, 2000; Prasad et al. 2013, 2015). However, in the present study, we will use the Chemical Ablation Model (CABMOD, Vondrak et al. 2008) to understand the ablation of major and minor elements and the thermal history that a meteoroid of specified mass, velocity and entry angle undergoes during flight through the atmosphere before landing on the Earth's surface as a micrometeorite. CABMOD takes into account sputtering of atoms by high velocity inelastic collisions with air molecules, followed by the onset of particle melting, which leads to the more rapid evaporative loss of atoms and oxides as a function of altitude.

\section{SAMPLE COLLECTION AND ELECTRON MICROSCOPY}

The samples were collected from Antarctica and deep sea sediments using different collection techniques. The Antarctica micrometeorites (AMM) were collected from the South Pole Water Well (SPWW), which has a diameter of $\sim 24 \mathrm{~m}$ at a depth of $\sim 100 \mathrm{~m}$ below the snow surface, with a total water volume of $\sim 5000 \mathrm{~m}^{3}$ (Taylor et al. 1998, 2000). The cosmic spherules from deep sea sediments (CS-DSS) were collected at water depths of $\sim 5200 \mathrm{~m}$ using an Okean grab sampler with a seafloor penetration depth of $\sim 15 \mathrm{~cm}$ (Rudraswami et al. 2012, 2014, 2015a; Prasad et al. 2013). The AMM and CS-DSS have been dated at $\sim 900$ years BP and 0-50,000 years BP, respectively (Taylor et al. 1998, 2007; Prasad et al. 2013). The samples were mounted in epoxy and were gradually ground until the particles were sectioned diametrically. The CS-DSS were initially size sorted under a binocular microscope so that, while grinding, all samples received equal area exposure and no small sized samples were lost due to over polishing to expose larger-sized samples. One epoxy section of AMM was mounted with $\sim 1200$ particles, while 27 epoxy mounts were prepared for the deep sea spherules that accommodated $\sim 5000$ particles to scan for Mg-rich olivines $(\mathrm{Fo}>95 \%)$.

Each particle was examined in detail using back-scattered electron (BSE) images obtained by a JEOL JSM 5800LV SEM with an OXFORD INCA Energy Dispersive Spectrometer detector (EDS, ISIS-300), in order to systematically identify the Mg-rich mineral phases. These were further analyzed using a Cameca SX5 Electron Micro Probe Analyzer to obtain the chemical composition. Selected minor elements were analyzed for longer counting times to improve the detection limits. Multiple analyses were done on most of the relict olivine grains (depending on the grain size); these analyses were then averaged. Both electron microscopy instruments are housed at the National Institute of Oceanography (NIO), Goa.

\section{RESULTS}

Relict olivine are Mg-rich olivine (Fo > 95\%) grains that are not formed from crystallization during atmospheric entry. They are distinctive in the spherule and can be easily identified from their large grain size, morphology, chemical composition, and their association with the presence of $\mathrm{Fe}, \mathrm{Ni}$-metals enclosed within these grains. Mg-rich olivines are largely found in unmelted, scoriaceous, and porphyritic micrometeorites. Nearly 5000 particles from AMM and CS-DSS were examined using BSE images and EDS to recognize Mg-rich olivines, which were then further analyzed with the electron microprobe to understand the variability of their chemical composition and the nature of the precursors contributing to these micrometeorites. CS-DSS particles have to survive the harsh seafloor conditions, which suggests that the more fragile particles have fallen recently. CS-DSS have $\mathrm{Mg}$-rich olivines that are of relatively small sizes so that large numbers of specimens had to be scanned under the SEM to collect a sizeable number of $\mathrm{Mg}$ rich olivines. AMM usually have larger forsteritic olivines occurring in greater numbers. The selected Mg-rich olivines are angular in shape with no textural alteration, and typically occupy a large area of the spherule. Representative BSE images of micrometeorites, which contain relict olivines, collected from SPWW and DSS, are shown in Figure 1 and their chemical composition are given in Table 1.

Although the olivine grain has a wide range in composition, we consider here a narrow range of forsteritic composition (Fo $=95 \%-100 \%)$. The bulk chemical composition of the spherules are significantly different from that of the Mg-rich olivine, with high $\mathrm{Al}, \mathrm{Ca}, \mathrm{Fe}$, and $\mathrm{Ni}$ abundances. We selected 182 olivine grains from 63 AMM and 238 grains from $162 \mathrm{CS}$ DSS to provide useful statistical control on the types of precursors (Table 1). All Mg-rich olivines are collected as part of a systematic study to understand the distribution of minor elements. A majority of the relict olivines from AMM and CSDSS have $\mathrm{Cr}_{2} \mathrm{O}_{3}, \mathrm{MnO}$, and $\mathrm{CaO}$ ranging from $0.1-0.7 \mathrm{wt} \%$, $0.0-0.3 \mathrm{wt} \%$, and $0.1-0.3 \mathrm{wt} \%$, respectively (Figures 2 and 3). The relict olivines in micrometeorites collected from Antarctica and deep sea sediments show similar patterns. The bulk chemical composition of particles from AMM and CS-DSS 

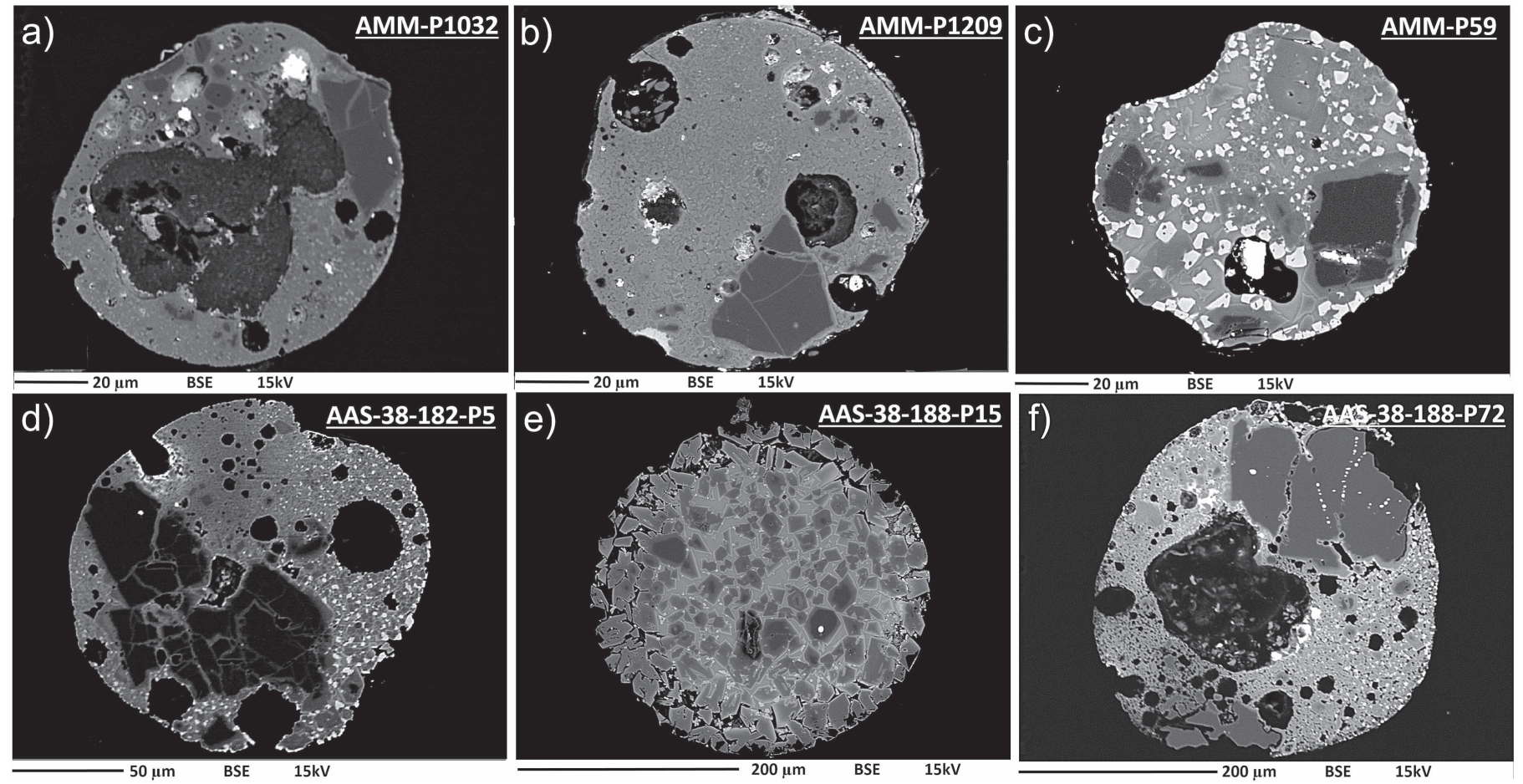

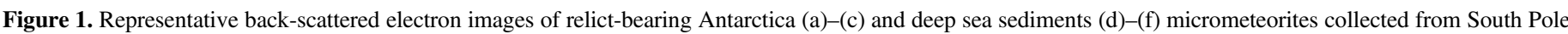
Water Well (SPWW) and Indian Ocean. The large relict grain stands clearly noticeable in the micrometeorites.

was determined using the Lispix software program, which shows that the major element compositions are close to $\mathrm{CI}$ chondrites. Some unmelted particles or single grains from AMM deviate from the CI values (Rudraswami et al. 2015a). The minor elements in $\mathrm{Mg}$-rich olivine behave as follows: $\mathrm{CaO}$ correlates with $\mathrm{Al}_{2} \mathrm{O}_{3}$ (Figures 2(a), 3(a)), and $\mathrm{CaO}$ seems to anti-correlate with $\mathrm{Cr}_{2} \mathrm{O}_{3}$ and $\mathrm{MnO}$ (Figures 2(b), (d), 3(b), (d)), as with the increase of $\mathrm{CaO}$, there is a decrease of $\mathrm{Cr}_{2} \mathrm{O}_{3}$ and $\mathrm{MnO} ; \mathrm{Cr}_{2} \mathrm{O}_{3}$ correlates with $\mathrm{MnO}$ (Figures 2(c), 3(c)); and $\mathrm{FeO}$ seems to correlate with $\mathrm{MnO}$ and $\mathrm{Cr}_{2} \mathrm{O}_{3}$ (Figures 2(e), (f), $3(\mathrm{e}),(\mathrm{f}))$. There is a slight spread in the $\mathrm{FeO}$ data as this oxide has been affected to some extent during atmospheric entry. The size (diameter in $\mu \mathrm{m}$ ) of the micrometeorites, size (length and breadth in micrometer) of relict grain, and chemical composition of the relict olivine grain are provided in the Appendix and in Figure 4. There are some micrometeorites that are single mineral and hence the relict grain sizes are comparable to the size of micrometeorites themselves. Some micrometeorites with relict grains have irregular external shapes, in such circumstance, we have reported the maximum length $(\mu \mathrm{m})$ of the particle, which is self-explanatory.

\section{DISCUSSION}

\subsection{Relict Olivine in Micrometeorites}

The presence of relict grains in many micrometeorites indicates that the grains did not re-crystallize during their high temperature atmospheric entry, but are preserved from their original formation (Genge et al. 2008). The forsterites in micrometeorites are not in equilibrium with the surrounding melt during atmospheric entry and may not have crystallized from the spherule composition that is Fe-rich. The forsterites have escaped melting because they are more refractory and were heated for a short time during atmospheric entry, so that the relatively large relict grains were not resorbed into the molten material. Heating followed by fast cooling therefore retained the minor chemical components in the grains, which would otherwise have easily diffused away. These grains are the basic components of the chondrules from which they have apparently formed (Steele 1986, 1992; Brearley \& Jones 1998; Wasson \& Rubin 2003; Hewins et al. 2005; Jones \& Carey 2006), so that the forsterite provides significant clues about precursors to the flux of micrometeorites.

The present discussion is centered on understanding what types of precursors contribute to the $\mathrm{Mg}$-rich grains in micrometeorites, and a comparison is made with the existing data for C1 (CI), C2 (CM), and C3 (CV) chondrites (Rubin \& Wasson 1986; Steele 1986, 1990; Kurat et al. 1989; Jones \& Carey 2006; Russell et al. 2010; Rudraswami et al. 2011). Olivine is the dominant phase in chondrules, namely type I ( $\mathrm{FeO}$ poor with $\mathrm{Fa}<10 \%$ ) and $\mathrm{II}$ ( $\mathrm{FeO}$ rich with $\mathrm{Fa}>10 \%$ ), and the olivine varies in composition from $\mathrm{Mg}$-rich to $\mathrm{Mg}$-poor (Hewins 1997). Mg-rich olivines are common in type I chondrules that are abundant $(>90 \%)$ in all types $(\mathrm{CM}, \mathrm{CO}$, $\mathrm{CV}$, and CR) of carbonaceous chondrites (CCs; Scott \& Krot 2005). Unequilibrated ordinary chondrites (UOCs) rarely contain Mg-rich olivine. The chondrules that are surrounded by fine-grained matrix are dominated by Fe-rich olivine. The $\mathrm{Mg}$ rich forsterites represent chondrule precursors that are not thermally altered and have witnessed and survived the chondrule forming event (Jones 1996). The Mg-rich olivines are supposed to be the major silicates in chondrules formed from the high temperature condensate in a stellar outflow, and are the early major condensate (Steele 1986). The minor elemental composition of Mg-rich olivines in CCs allows the Mg-rich olivine of chondrules and its components to be compared. In the present study, we have compared Mg-rich 

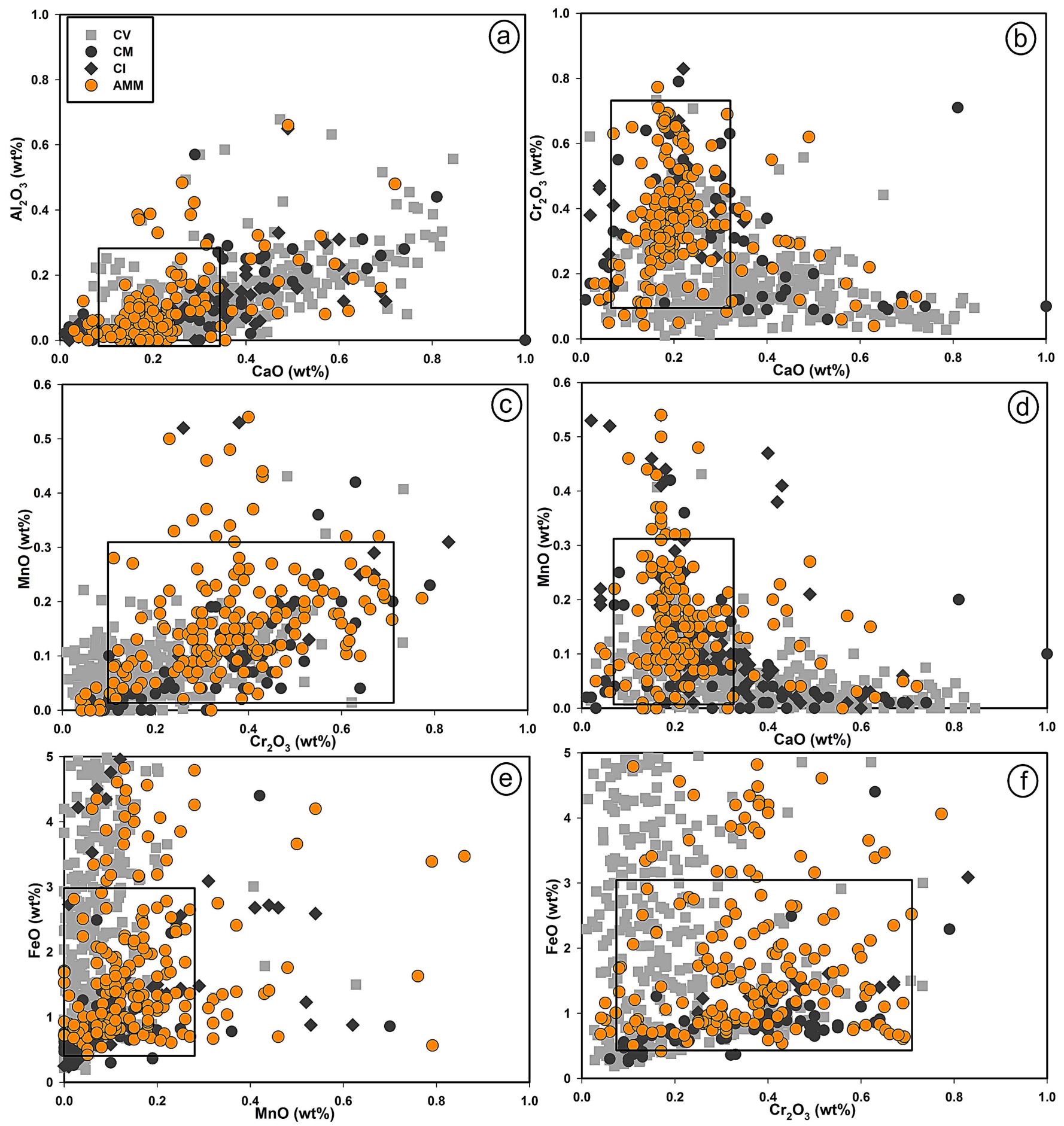

Figure 2. Minor element $\left(\mathrm{CaO}, \mathrm{Al}_{2} \mathrm{O}_{3}, \mathrm{Cr}_{2} \mathrm{O}_{3}, \mathrm{MnO}\right.$, and $\left.\mathrm{FeO}\right)$ of relict olivine from $\mathrm{AMM}$ in comparison with olivines of $\mathrm{CI}, \mathrm{CM}$, and $\mathrm{CV}$ chondrites. The rectangle is the region where the likelihood of finding the particle within it is maximum. The data for chondrites are taken from the literature (Rubin \& Wasson 1986; Steele 1986, 1990; Kurat et al. 1989 Jones \& Carey 2006; Russell et al. 2010; Rudraswami et al. 2011).

olivine from chondrules of CI (Orgueil and Tagish lake), CM (Murchison and Yamato 82042), and CV3 (Allende and Mokoia) chondrites. The minor elements such as $\mathrm{MnO}, \mathrm{CaO}$, $\mathrm{Al}_{2} \mathrm{O}_{3}$, and $\mathrm{Cr}_{2} \mathrm{O}_{3}$, and the $\mathrm{FeO}$ in $\mathrm{Mg}$-rich olivine of $\mathrm{Cl}$ chondrites are indistinguishable from those of $\mathrm{C} 2$, hence it may be difficult to narrow down based on the chemistry (Steele et al. 1985a; Steele 1990, 1992). The olivines in CI are small, rare and are embedded in matrix, hence we do not consider CIchondrite to be contributing to relict-bearing particles. The olivine in the chondrules of UOCs has a forsterite content predominantly in the range of $70 \%-90 \%$. The olivines in UOCs also have low $\mathrm{CaO}$ content, hence an insignificant number of micrometeorites can be related to ordinary chondrites (Beckerling \& Bishcoff 1995). The above conclusion is also supported by oxygen isotopic studies on relict olivine in micrometeorites that fall in the range of the chondrule from carbonaceous chondrites rather than ordinary chondrites (e.g., Rudraswami et al. 2015b, 2016). 

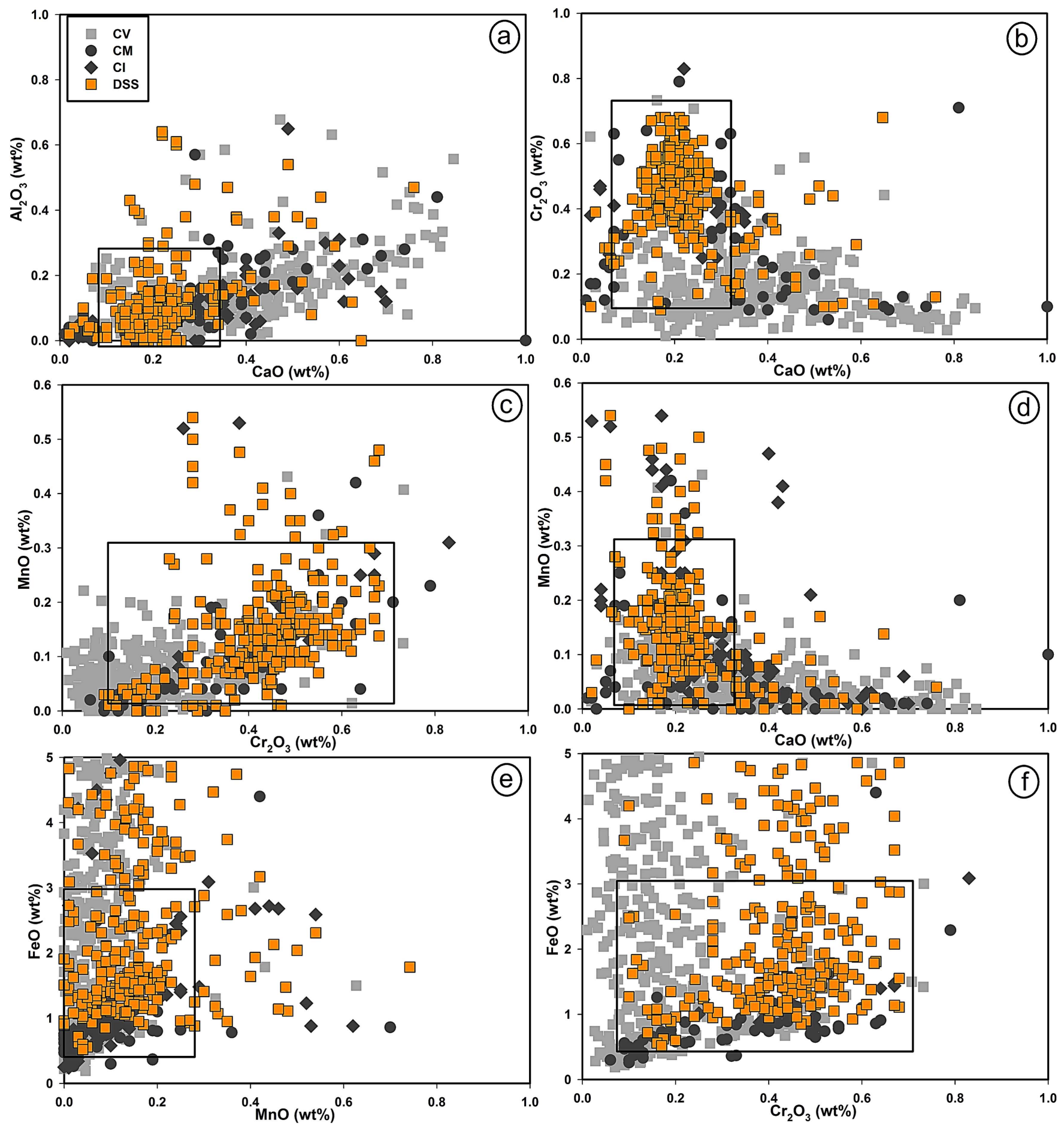

Figure 3. Minor element $\left(\mathrm{CaO}, \mathrm{Al}_{2} \mathrm{O}_{3}, \mathrm{Cr}_{2} \mathrm{O}_{3}, \mathrm{MnO}\right.$, and $\left.\mathrm{FeO}\right)$ of relict olivine from DSS in comparison with olivines of CI, $\mathrm{CM}$, and $\mathrm{CV}$ chondrites. The rectangle is the region where the likelihood of finding the particle within it is maximum. The data for chondrites are taken from the literature (Rubin \& Wasson 1986; Steele 1986, 1990; Kurat et al. 1989 Jones \& Carey 2006; Russell et al. 2010; Rudraswami et al. 2011).

Forsteritic olivines in CI chondrites are rare and small in size (Steele 1990) and are closely associated with CM rather than CV chondrites (Steele 1985a, 1985b, 1990). Henceforth, data from the present study are compared only with $\mathrm{CM}$ and $\mathrm{CV}$ chondrites. The general data suggest that relict-bearing micrometeorites are strongly correlated with the $\mathrm{CV}$ chondrule data, but there are certain regions that are common to both $\mathrm{CM}$ and $\mathrm{CV}$ data. The data overlap with the $\mathrm{C} 2$ and $\mathrm{C} 3$, as suggested by Steele et al. (1985a, 1985b). The majority of the forsterites in
$\mathrm{CV}$ chondrules have $\mathrm{Cr}_{2} \mathrm{O}_{3}$ and $\mathrm{MnO}$ contents confined to narrow ranges of $0.0-0.3 \mathrm{wt} \%$ and $0.0-0.1 \mathrm{wt} \%$, respectively. The ranges in $\mathrm{CM}$ chondrules are $0.0-0.8 \mathrm{wt} \%$ and $0.0-0.3$ $\mathrm{wt} \%$, respectively. The forsterites in most micrometeorites fall close to the $\mathrm{CM}$ region. This is also true for the $\mathrm{CaO}$ versus $\mathrm{Cr}_{2} \mathrm{O}_{3}$ and $\mathrm{MnO}$ plots (Figures 2 and 3). Earlier work done by Steele et al. (1985a, 1985b) and Steele (1992) analyzed a small number of olivines (a total of $~ 64$ ) for different studies. They concluded that micrometeorites are largely related to C2 

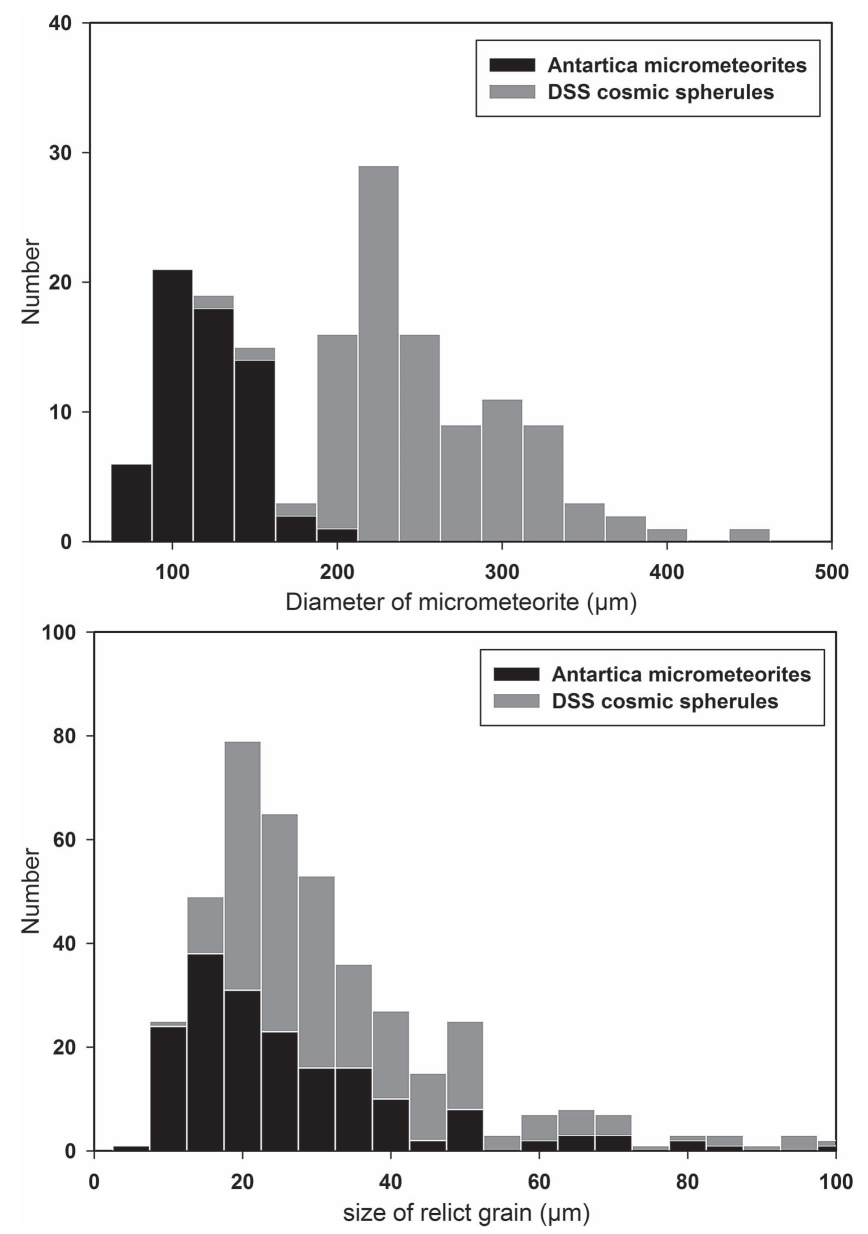

Figure 4. Histogram plot of the size of micrometeorites (top) and the relict grain (bottom) collected from Antarctica and deep sea sediments.

chondrites, with some contribution of C3- and UOC-type chondrites. An overwhelming majority of forsterites from micrometeorites in the present study cluster in the narrow range shown by the rectangles in Figures 2 and 3, displaced slightly from C3 data and displaying an affinity to $\mathrm{C} 2$ forsterites, though not completely. The observation of clustering of the data is statistically significant because it points toward the possibility that the micrometeorites largely originate from a group of asteroids that have forsteritic chemical compositions lying in a restricted range. These types of asteroids would be fragile or enriched in the regolith layer, thereby producing a larger amount of dust particles into interplanetary space during collision. Among the chondrules, type I in C2 and C3 contribute up to $\sim 90 \%$, while the remaining $\sim 10 \%$ are of type II (Jones 2012). The large size of the forsterites in the present study is also suggestive of their derivation from the type I chondrules in $\mathrm{C} 2$ and $\mathrm{C} 3$, which have a high abundance of forsterites that are large in size. Overall, the forsterites seem to be part of the chondrule precursor material and have not been recycled during chondrule formation and later during incorporation into parent bodies. These grains may have escaped catastrophic collisions in the asteroid belt followed by atmospheric entry heating. Some forsterites have small fayalitic rims (approximately a few micrometers), which appear to have formed due to rapid alteration during their high temperature transit while entering the atmosphere, followed by fast cooling. This process essentially preserved the forsteritic cores. The relict-bearing, scoriaceous and porphyritic spherules have not experienced temperature greater than $1700 \mathrm{~K}$ during atmospheric entry. Hence the large-sized forsterite grains of these spherules do not seem to be in equilibrium with the FeO-rich surroundings from less than a few percent present in the core of the relict grain to as high as $10 \%-30 \%$ on the rim within the timeframe of atmospheric heating. A slow heating and cooling rate would have allowed $\mathrm{FeO}$ to diffuse into the forsterite and resulted in a loss of forsteritic identity. Another way would be to heat the meteoroid above $1900 \mathrm{~K}$ so that it completely melted. The atmospheric heating constraints related to the survival of the relict forsterite grains are discussed in the next section.

\subsection{Temperature, Size, and Entry Angle}

Extraterrestrial particles preserve the properties of the precursors and provide information that enhances our understanding of the solar system, provided the chemical compositions are intact and not altered during atmospheric entry. We explore the physical and chemical processes of the fragments of dust particles that have been incorporated in the Earth resonance orbit based on various entry parameters. Numerical calculation was done using the CABMOD model to examine the change in the chemical composition of the incoming particles as a function of mass, velocity, entry angle with respect to the zenith (ZA), and particle density (Vondrak et al. 2008). This involved exploring the parameter space of these variable to determine the conditions under which relict grains would survive atmospheric entry. The principal goal of earlier model studies was to look into the ablation of the particles and the temperature experienced during various entry velocities (Flynn 1989a, 1989b; Love \& Brownlee 1991). CABMOD determines the ablation rates of individual elements ( $\mathrm{Mg}, \mathrm{Fe}, \mathrm{Si}, \mathrm{Ca}, \mathrm{Al}, \mathrm{Ti}, \mathrm{Na}$, and $\mathrm{K}$ ) along the meteor track from an initial altitude of $500 \mathrm{~km}$. In the present study, we also consider the amount of time the particle remains within $100 \mathrm{~K}$ of the peak temperature, the cooling rate, and the deviation from initial chemical composition of the particle during its journey through the upper atmosphere. For these model runs, a CI composition is used with a particle density of $2 \mathrm{~g} \mathrm{~cm}^{-3}$ (Mason 1971; Sears \& Dodd 1988; Lodders \& Fegley 1998; Vondrak et al. 2008). The present study considers the smallest particle size of $\sim 100 \mu \mathrm{m}$ in diameter that we can work with comfortably and the largest size of $\sim 700 \mu \mathrm{m}$. It should be noted that the size of the particle is synonymous to the diameter of the particle. Larger size particles (diameter $>$ ca. $100 \mu \mathrm{m}$ ) can undergo extensive melting and vaporization depending on the ZA and entry velocity. Here we have restricted the entry velocity $16 \mathrm{~km} \mathrm{~s}^{-1}$, beyond which the particles (sizes ranging from 100 to $700 \mu \mathrm{m}$ ) lose substantial mass and undergo significant compositional change (Rudraswami et al. 2015b).

The particle ZA has a large effect on the thermal profile during entry. Entering at $\mathrm{ZA}=0^{\circ}$, a particle will heat and cool faster than when entering at the grazing angle $\left(\mathrm{ZA}=90^{\circ}\right)$. The time the particle remains within $100 \mathrm{~K}$ of the peak temperature varies from 0.5 to $1 \mathrm{~s}$, depending on the $\mathrm{ZA}$ and size of the particle. Larger particles spend less time close to the peak temperature compared to smaller particles entering with the same ZA and velocity.

A cooling rate of $\sim 300-500 \mathrm{~K} \mathrm{~s}^{-1}$ for any ZA means that the particle temperature drops rapidly below $600 \mathrm{~K}$ within a few seconds. Thus, the heating up to the peak temperature of 


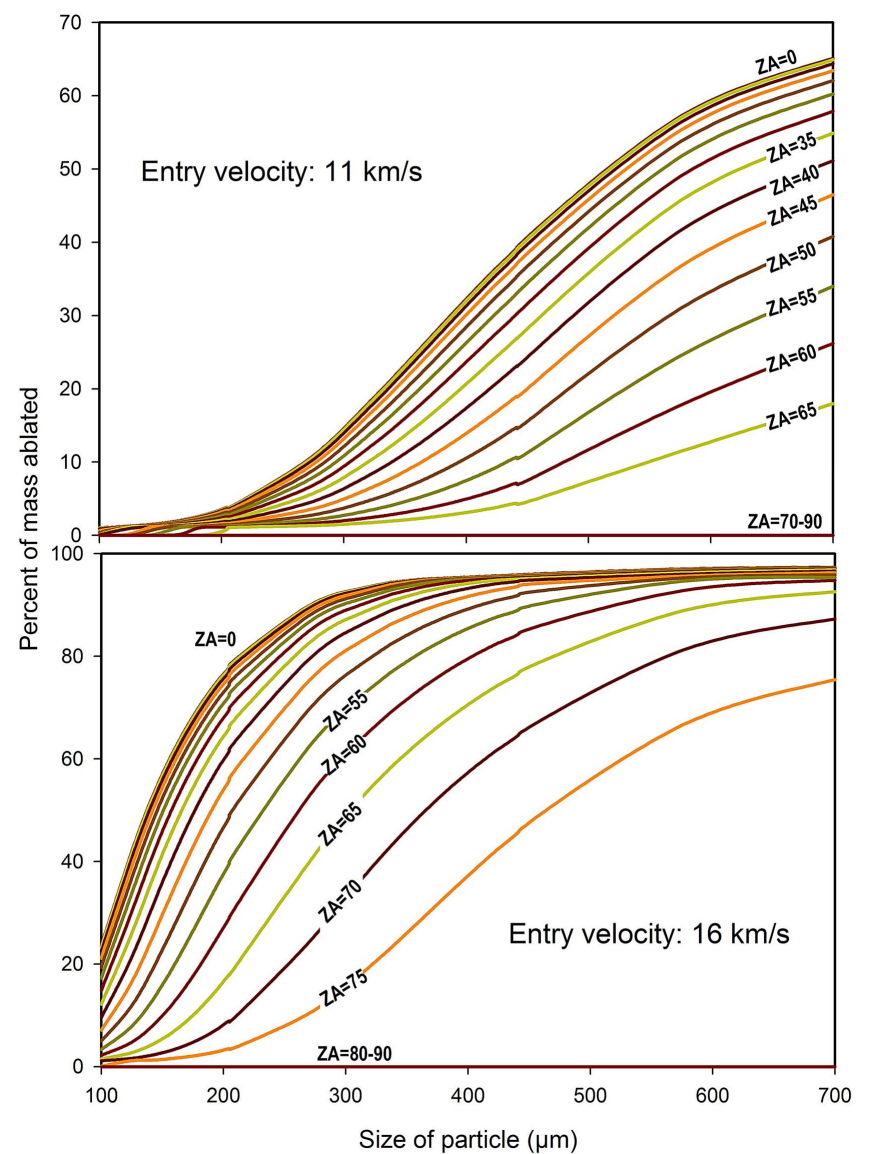

Figure 5. Distribution of percent of mass ablation for different size in diameter of entry particle over a range of $\mathrm{ZA}=0^{\circ}$ and $90^{\circ}$ with entry velocities 11 and $16 \mathrm{~km} \mathrm{~s}^{-1}$.

$<1700 \mathrm{~K}$ in relict-bearing, scoriaceous, and porphyritic particles should not cause changes in the initial composition of relict forsteritic grains, in contrast to the bulk chemical composition, which is altered by ablation (Figures 2-3). This is not the only parameter that is paramount, it is also concomitant with entry mass and velocity. Particles of diameter less than $200 \mu \mathrm{m}$ and entry velocity $11 \mathrm{~km} \mathrm{~s}^{-1}$ undergo ablation of only a few percent at any ZA; however, as size increases only those particles that enter at high ZA $\left(70^{\circ}-90^{\circ}\right)$ are well preserved (Figure 5). Conversely, for $16 \mathrm{~km} \mathrm{~s}^{-1}$, particle ablation is high for small size particles $(\sim 100 \mu \mathrm{m})$, apart from an even narrower range of $\mathrm{ZA}\left(80^{\circ}-90^{\circ}\right)$ (Figure 5).

The bulk $\mathrm{Ca} / \mathrm{Si}$ (atomic) and $\mathrm{Al} / \mathrm{Si}$ (atomic) ratios are close to the solar composition irrespective of the type of cosmic spherule (Rudraswami et al. 2015b). However, Mg-rich olivine is different from the bulk chemical composition of the particle. Even if the spherule has experienced a temperature as high as $1700 \mathrm{~K}, \mathrm{Mg}$-rich olivine will escape chemical alteration due to its large size and brief heating time during atmospheric entry. Such grains potentially record the original composition when they formed in solar nebula. Two different entry velocities of 11 and $16 \mathrm{~km} \mathrm{~s}^{-1}$ are considered in the present study, as with faster particles complete ablation occurs (Vondrak et al. 2008; Rudraswami et al. 2015b).

The first stage of heating results in the loss of Fe followed by $\mathrm{Si}$ and $\mathrm{Mg}$, which is the reason for the increase in the $\mathrm{Mg} / \mathrm{Si}$ ratio (Hashimoto 1983; Rudraswami et al. 2015b). The Fe loss is too large compared to other major elements like $\mathrm{Si}$ and $\mathrm{Mg}$,

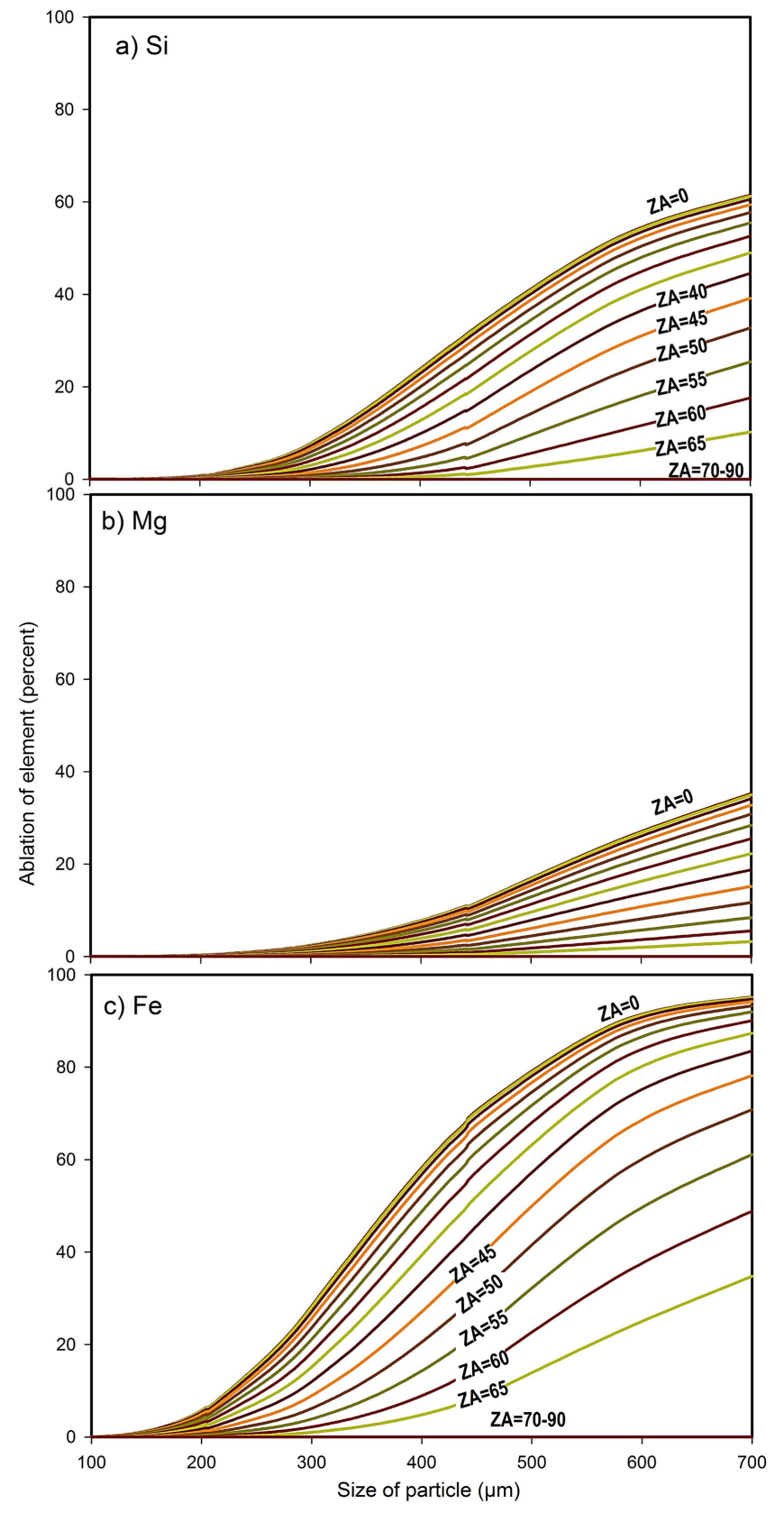

Figure 6. Elemental ablation of $\mathrm{Si}, \mathrm{Mg}$, and $\mathrm{Fe}$ for different sizes of particle over a range of $\mathrm{ZA}=0^{\circ}$ and $90^{\circ}$, for an entry velocity of $11 \mathrm{~km} \mathrm{~s}^{-1} . \mathrm{Ca}, \mathrm{Al}$, and $\mathrm{Ti}$ do not exhibit significant ablation and hence are not included in the plot.

resulting in an increase in $\mathrm{Ca}$ and $\mathrm{Al}$ (Figures 6-7). The ternary $\mathrm{Mg}-\mathrm{Fe}-\mathrm{Si}$ plot in Figure 8 illustrates how the loss of Fe varies as a function of size, ZA, and velocity. The loss of Fe results in a relative increase in $\mathrm{Si}$ and $\mathrm{Mg}$, which changes the bulk chemical composition from olivine stoichiometry to that of pyroxene (Hashimoto 1983). Ablation of the refractory elements such as $\mathrm{Ca}, \mathrm{Al}$, and $\mathrm{Ti}$ depend on the particle mass, ZA and entry velocity (Figure 7). The ablation of these elements is negligible for a velocity of $11 \mathrm{~km} \mathrm{~s}^{-1}$ irrespective of the size and $\mathrm{ZA}$, even when the major elements $\mathrm{Si}, \mathrm{Mg}$, and $\mathrm{Fe}$ have largely ablated (Figure 6). At $16 \mathrm{~km} \mathrm{~s}^{-1}$, the refractory elements like $\mathrm{Ca}, \mathrm{Al}$, and $\mathrm{Ti}$ do not show ablation for particles sizes less than $400 \mu \mathrm{m}$ irrespective of $\mathrm{ZA}$, but there is large-scale ablation for $\mathrm{Si}, \mathrm{Mg}$, and $\mathrm{Fe}$ (Figure 7). $\mathrm{Al}$ is the 

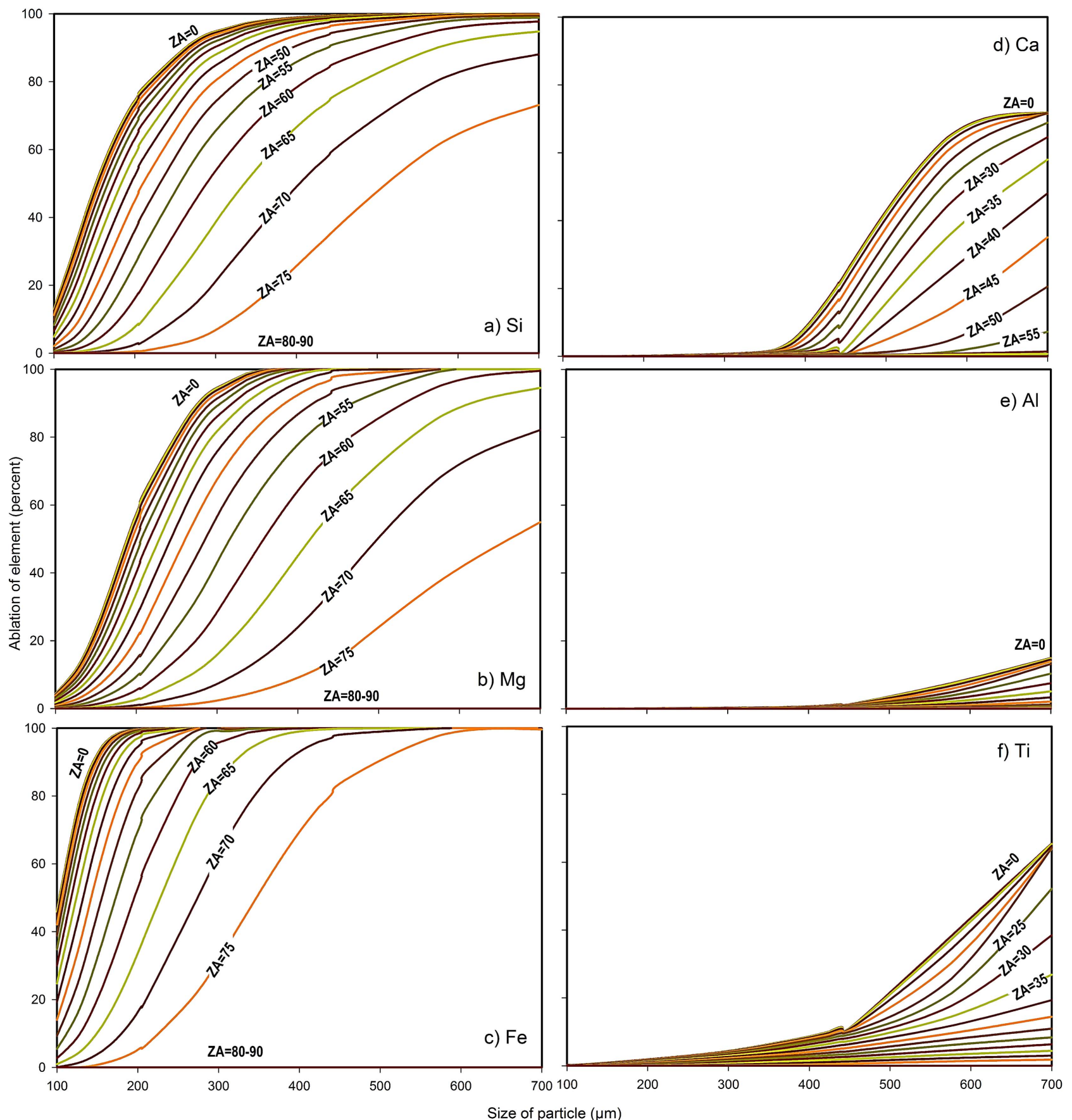

Figure 7. Elemental ablation of $\mathrm{Si}, \mathrm{Mg}, \mathrm{Fe}, \mathrm{Ca}, \mathrm{Al}$, and $\mathrm{Ti}$ for different sizes of entry particles over a range of $\mathrm{ZA}=0^{\circ}$ and $90^{\circ}$, for an entry velocity of $16 \mathrm{~km} \mathrm{~s}{ }^{-1}$.

most robust of these elements for those sizes followed by $\mathrm{Ca}$ and $\mathrm{Ti}$. Ti ablates by a few percent for smaller sizes at $\mathrm{ZA}<50^{\circ}$; $\mathrm{Ca}$ ablation starts for particles greater than $\sim 400 \mu \mathrm{m}$ and rises rapidly beyond $500 \mu \mathrm{m}$. Al does not undergo ablation for any zenith angle for $\sim 450 \mu \mathrm{m}$ and rises slightly to only a few percent at $600 \mu \mathrm{m}$, for $\mathrm{ZA}<30^{\circ}$. For most of the micrometeorites analyzed, with sizes below $300 \mu \mathrm{m}$, Ca and Al have most likely undergone no ablation, and Ti only a small amount (Figure 7). This suggests that the chemical composition of the minor refractory elements will have been preserved even after the particle has been heated to $\sim 1700 \mathrm{~K}$ irrespective of the ZA; though, the particle undergoes large-scale vaporization of $\mathrm{Si}, \mathrm{Mg}$, and $\mathrm{Fe}$, thereby unbalancing the chemical composition (Figures 6-8).
For an entry velocity of $16 \mathrm{~km} \mathrm{~s}^{-1}$ there is a limited range of $\mathrm{ZA}$ for which the total ablation is less than $20 \%$. For a $200 \mu \mathrm{m}$ particle, the $\mathrm{ZA}$ is $>65^{\circ}$, while for a $300 \mu \mathrm{m}$ particle $\mathrm{ZA}>70^{\circ}$. For $\mathrm{ZA}=70^{\circ}-80^{\circ}$, the temperature reaches $\sim 1700 \mathrm{~K}$ resulting in ablation of $\sim 1 \%-8 \%$ in the size range of the micrometeorites we have analyzed (Rudraswami et al. 2015b). The small olivine grains at these temperatures will have mobilized elements, but the large-sized forsterites are temperature resistant, as is obvious from the behavior of their chemical compositions (Figures 2-3). Faster cooling has also prevented diffusion to the neighboring phases. At very high ZA $\left(80^{\circ}-90^{\circ}\right)$, there is a smooth entry with no ablation. Overall, a $\mathrm{ZA}>65^{\circ}$ is ideal for a particle size up to $\sim 200 \mu \mathrm{m}$, since the relict olivine will be retained in its original chemical 


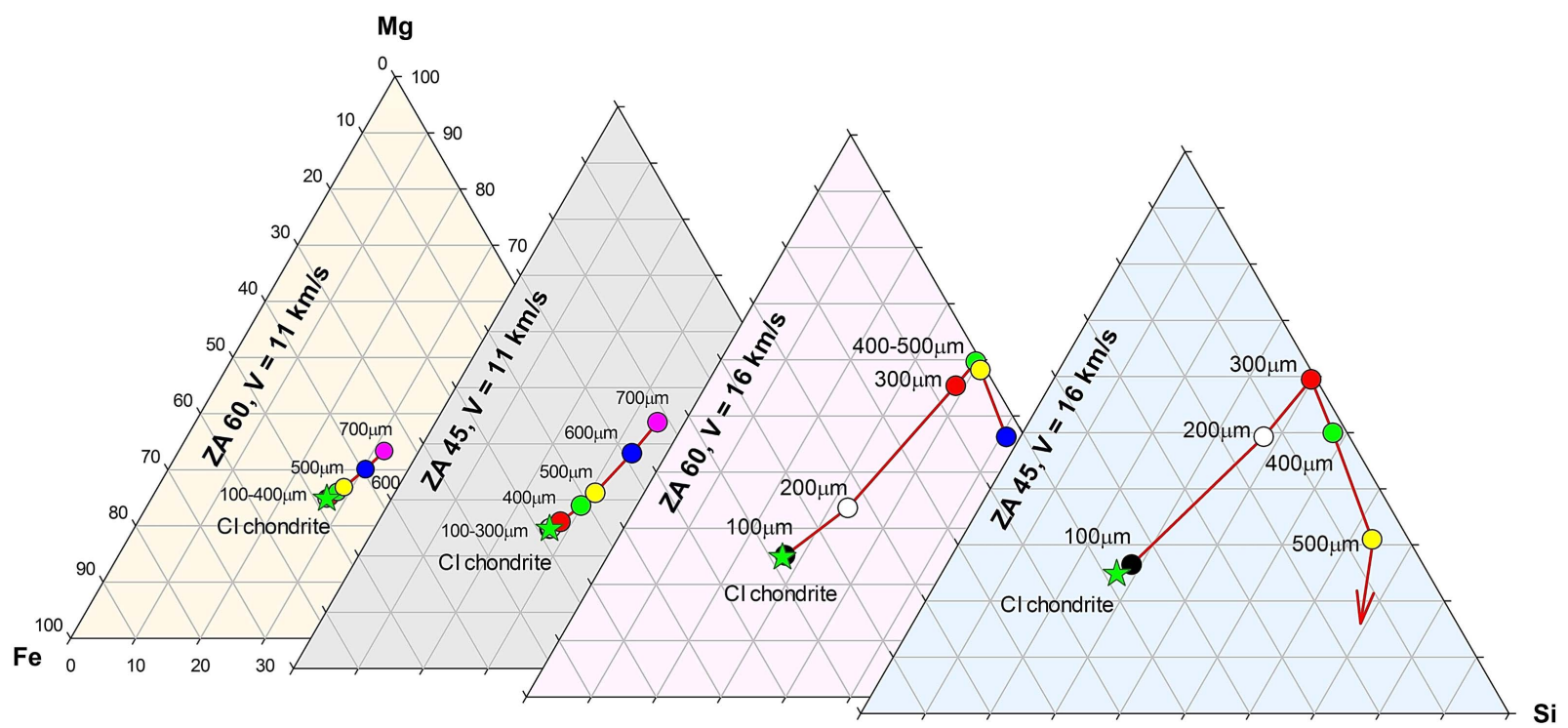

Figure 8. Ternary diagram representing $\mathrm{Mg}-\mathrm{Si}-\mathrm{Fe}$ of different sizes of particles for $\mathrm{ZA}=45^{\circ}$ and $60^{\circ}$ and entry velocities 11 and $16 \mathrm{~km} \mathrm{~s}{ }^{-1}$. A CI chondritic composition is used as the starting material.

composition. However, particles larger than $300 \mu \mathrm{m}$ will experience a temperature above the liquidus state $(>1900 \mathrm{~K})$ for a relatively long time (less than a few seconds) depending on the ZA and entry, as it penetrates deeper into the atmosphere, so that relict minerals will tend to lose their identity and homogenize with the bulk chemical composition. As the ZA goes on increasing, the given size particle will spend more time at peak temperature. In general, the time spent at peak temperature, where most particles attain the liquidus temperature, will be less than 1 and $2 \mathrm{~s}$ for 11 and $16 \mathrm{~km} \mathrm{~s}^{-1}$, respectively. The AMM has a size range from $\sim 50-200 \mu \mathrm{m}$, while that of CS-DSS has a size range from $\sim 150-400 \mu \mathrm{m}$ and a few beyond. The histogram plot in Figure 4 indicates AMM and CS-DSS has a peak of $\sim 100 \mu \mathrm{m}$ and $220 \mu \mathrm{m}$, respectively. The majority of the relict grain has a size range of $\sim 10-40 \mu \mathrm{m}$, irrespective of micrometeorite size range (Figure 4). The large size relict grain is from the single mineral micrometeorite where the ablation of the micrometeorite is much smaller with no change in chemical composition. The entry velocity of $11 \mathrm{~km} \mathrm{~s}^{-1}$ and $\mathrm{ZA}=65^{\circ}$, the micrometeorites with sizes from $\sim 50-400 \mu \mathrm{m}$ will be perfect for preserving the relict grain as the volatile element $\mathrm{Fe}$ does not get ablated. On the other hand, for an entry velocity at $16 \mathrm{~km} \mathrm{~s}^{-1}$ to preserve the relict grain with chemical composition, the range of $\mathrm{ZA}$ is $\sim 70^{\circ}-90^{\circ}$ for micrometeorites sizes $<100 \mu \mathrm{m}, \mathrm{ZA}>75^{\circ}$ for $\sim 100-200 \mu \mathrm{m}$, and $\mathrm{ZA}=80^{\circ}-90^{\circ}$ for sizes $>200 \mu \mathrm{m}$. The relict-bearing particles, which are decisive in revealing the precursor of the particles they belong to, have a strict entry parameters in terms of entry velocity, ZA, and size as discussed above.

\section{CONCLUSIONS}

Mg-rich olivine (Fo > 95\%) in AMM and CS-DSS is unusual and can be easily distinguished from the neighboring grains. The Fo-rich grains and their chemical composition suggests that the high temperatures experienced by the meteoroid during atmospheric entry has not altered the minor elemental compositions of these olivines. The forsterites that are widespread in chondrules and also found in micrometeorites, which suggests a major contribution from chondrule components of $\mathrm{CCs}$ like $\mathrm{CV}$ chondrules and forsterites from $\mathrm{CM}$ chondrites, rather than CI chondrites. The composition data of the $\mathrm{Mg}$-rich olivines indicate frequent collisions between a similar group of asteroids that generated dust having $\mathrm{Mg}$-rich olivines in a narrow range of $\mathrm{Al}_{2} \mathrm{O}_{3}, \mathrm{CaO}$, $\mathrm{MnO}$, and $\mathrm{Cr}_{2} \mathrm{O}_{3}$ relative abundances, slightly different from $\mathrm{CM}$ and $\mathrm{CV}$ carbonaceous chondrites. The systematic deviation of the bulk composition suggests that relict grains in scoriaceous and porphyritic micrometeorites are more resistant to the heating experienced by micrometeorites. The CABMOD simulations indicate that particles smaller than $300 \mu \mathrm{m}$ with entry velocities less than $16 \mathrm{~km} \mathrm{~s}^{-1}$ and large $\mathrm{ZA}\left(70^{\circ}-90^{\circ}\right)$ are likely to preserve the relict minerals.

This work is supported by the CSIR XII Plan funded Project GEOSINKS and the PLANEX project, Physical Research Laboratory, Ahmedabad (NGR and MSP). We thank Vijay Khedekar for his support in EPMA and electron microscopy. The CABMOD model development is supported by the European Research Council (project 291332-CODITA). The National Science Foundation funded the collection of micrometeorites from the South Pole water well. This is NIO's contribution No. 5941.

\section{APPENDIX}

The table includes size (diameter in micrometers) of micrometeorites, length (micrometers) and breadth (micrometers) of the relict grains analyzed in the present study along with chemical composition of the relict grain. Multiple analyses are done on these relict grains, which are averaged.

\section{REFERENCES}

Beckerling, W., \& Bischoff, A. 1995, P\&SS, 43, 435

Brearley, A. J., \& Jones, R. H. 1998, in Reviews in Mineralogy Vol. 36, ed. J. J. Papike (Washington, DC: Mineral. Soc. America), 3-001 
Brownlee, D. E. 2001, in Acretion of Extraterrestrial Matter Throughout Earth's History, ed. B. Peucker-Ehrenbrink \& B. Schmitz (New York: Kluwer)

Brownlee, D. E., Bates, B., \& Schramm, L. 1997, M\&PS, 32, 157

Dermott, S. F., Jayaraman, S., Xu, Y. L., Gustafson, B. A. S., \& Liou, J. C. 1994, Natur, 369, 719

Flynn, G. J. 1989a, LPSC, 19, 673

Flynn, G. J. 1989b, Icar, 77, 287

Genge, M. J., Engrand, C., Gounelle, M., \& Taylor, S. 2008, M\&PS, 43, 497

Hashimoto, A. 1983, GeocJ, 17, 111

Hewins, R. H. 1997, AREPS, 25, 61

Hewins, R. H., Connolly, H. C., Lofgren, G. E., Jr., \& Libourel, G. 2005, ASP

Conf. Ser. 341, Chondrites and the Protoplanetary Disk, ed. A. N. Krot, E. R. D. Scott, \& B. Reipurth (San Francisco, CA: ASP), 286

Jones, R. H. 1996, in Proc. Chondrules and the Protoplanetary Disk Conf., ed. R. Hewins, R. Jones, \& E. Scott (Cambridge: Cambridge Univ. Press)

Jones, R. H. 2012, M\&PS, 47, 1176

Jones, R. H., \& Carey, E. R. 2006, AmMin, 91, 1664

Kortenkamp, S. J., Dermott, S. F., Fogle, D., \& Grogan, K. 2001, in Accretion of Extraterrestrial Matter Throughout Earth's History, ed B. Peucker-Ehrenbrink \& B. Schmitz (New York: Kluwer)

Kurat, G., Koeberl, C., Presper, T., Brandstätter, F., \& Maurette, M. 1994, GeCoA, 58, 3879

Kurat, G., Mayr, M., Ntaflos, Th., \& Graham, A. L. 1989, Metic, 24, 35

Lodders, K., \& Fegley, B., Jr. 1998, The Planetary Scientist's Companion (New York: Oxford Univ. Press)

Love, S. G., \& Brownlee, D. E. 1991, Icar, 89, 26

Love, S. G., \& Brownlee, D. E. 1993, Sci, 262, 550

Mason, B. 1971, Handbook of Elemental Abundances of the Elements in Meteorites (London: Gordon and Breach)

Nesvorný, D., Janches, D., Vokrouhlický, D., et al. 2011, ApJ, 743, 129

Nesvorný, D., Jenniskens, P., Levison, H. F., et al. 2010, ApJ, 713, 816

Peucker-Ehrenbrink, B., \& Ravizza, G. 2000, GeCoA, 64, 1965

Plane, J. M. C. 2012, Chem. Soc. Rev., 41, 6507
Prasad, M. S., Rudraswami, N. G., Araujo, A., Babu, E. V. S. S. K., \& Vijaya Kumar, T. 2015, M\&PS, 50, 1013

Prasad, M. S., Rudraswami, N. G., \& Panda, D. K. 2013, JGR, 118, 2381

Reach, W. T., Franz, B. A., \& Weiland, J. L. 1997, Icar, 127, 461

Rubin, A. E., \& Wasson, J. T. 1986, GeCoA, 50, 307

Rudraswami, N. G., Prasad, S. M., Plane, J. M. C., et al. 2014, GeCoA, 131, 247

Rudraswami, N. G., Shyam Prasad, M., Babu, E. V. S. S. K., et al. 2012, GeCoA, 99, 78

Rudraswami, N. G., Shyam Prasad, M., Dey, S., et al. 2015a, ApJ, 814, 78

Rudraswami, N. G., Shyam Prasad, M., Jones, R. H., \& Nagashima, K. 2016, GeCoA, 194, 1

Rudraswami, N. G., Shyam Prasad, M., Nagashima, K., \& Jones, R. H. 2015b, GeCoA, 164, 53

Rudraswami, N. G., Ushikubo, T., Nakashima, D., \& Kita, N. T. 2011, GeCoA, 75,7596

Russell, S. D. J., Longstaffe, F. J., King, P. L., \& Larson, T. E. 2010, GeCoA, 74,2484

Scott, E. R. D., \& Krot, A. N. 2005, in Meteorites, Comets, and Planets, Treatise on Geochemistry, ed. A. M. Davis (Amsterdam: Elsevier), 143

Sears, D. W., \& Dodd, R. T. 1988, in Meteorites and the Early Solar System, ed. J. F. Kerridge \& M. S. Matthews (Tucson, AZ: Univ. Arizona Press)

Steele, I. M. 1986, GeCoA, 50, 1379

Steele, I. M. 1992, GeCoA, 56, 2923

Steele, I. M. 1990, Metic, 25, 1990

Steele, I. M., Smith, J. V., \& Brownlee, D. E. 1985a, Natur, 313, 297

Steele, I. M., Smith, J. V., \& Skirius, C. 1985b, Natur, 313, 294

Taylor, S., Lever, J. H., \& Harvey, R. P. 1998, Natur, 392, 899

Taylor, S., Lever, J. H., \& Harvey, R. P. 2000, M\&PS, 35, 651

Taylor, S., Matrajt, G., Lever, J. H., Joswiak, D., \& Brownlee, D. 2007, in ESA SP-643, Workshop on Dust Planetary Systems, ed. H. Krüger \& A. Graps (Paris: ESA), 26

Vondrak, T., Plane, J. M. C., Broadley, S., \& Janches, D. 2008, ACP, 8, 7015

Wasson, J. T., \& Rubin, A. E. 2003, GeCoA, 67, 2239

Yada, T., Nakamura, T., Takaoka, N., et al. 2004, EP\&S, 56, 67 